\title{
Broadband terahertz fiber directional coupler
}

Nielsen, Kristian; Rasmussen, Henrik K.; Jepsen, Peter Uhd; Bang, Ole

Published in:

Optics Letters

Link to article, DOI:

10.1364/OL.35.002879

Publication date:

2010

Document Version

Publisher's PDF, also known as Version of record

Link back to DTU Orbit

Citation (APA):

Nielsen, K., Rasmussen, H. K., Jepsen, P. U., \& Bang, O. (2010). Broadband terahertz fiber directional coupler. Optics Letters, 35(17), 2879-2881. https://doi.org/10.1364/OL.35.002879

\section{General rights}

Copyright and moral rights for the publications made accessible in the public portal are retained by the authors and/or other copyright owners and it is a condition of accessing publications that users recognise and abide by the legal requirements associated with these rights.

- Users may download and print one copy of any publication from the public portal for the purpose of private study or research.

- You may not further distribute the material or use it for any profit-making activity or commercial gain

- You may freely distribute the URL identifying the publication in the public portal

If you believe that this document breaches copyright please contact us providing details, and we will remove access to the work immediately and investigate your claim 


\title{
Broadband terahertz fiber directional coupler
}

\author{
Kristian Nielsen, ${ }^{1, *}$ Henrik K. Rasmussen, ${ }^{2}$ Peter Uhd Jepsen, ${ }^{1}$ and Ole Bang ${ }^{1}$ \\ ${ }^{1}$ Technical University of Denmark, DTU Fotonik, Department of Photonics Engineering, DK-280o Kgs. Lyngby, Denmark \\ ${ }^{2}$ Technical University of Denmark, DTU Mekanik, Department of Mechanical Engineering, DK-280o Kgs. Lyngby, Denmark \\ ${ }^{*}$ Corresponding author: krini@fotonik.dtu.dk
}

Received June 17, 2010; accepted July 12, 2010; posted August 2, 2010 (Doc. ID 130314); published August 20, 2010

We present the design of a short broadband fiber directional coupler for terahertz (THz) radiation and demonstrate a $3 \mathrm{~dB}$ coupler with a bandwidth of $0.6 \mathrm{THz}$ centered at $1.4 \mathrm{THz}$. The broadband coupling is achieved by mechanically downdoping the cores of a dual-core photonic crystal fiber by microstructuring the cores. This is equivalent to chemical downdoping but is easier to realize experimentally. (c) 2010 Optical Society of America OCIS codes: $060.5295,260.3090$.

Waveguides for terahertz $(\mathrm{THz})$ radiation [1] have attracted widespread attention in recent years, because the possibility of efficiently delivering and confining the $\mathrm{THz}$ radiation is one that offers many new applications. Consequently, there are now several demonstrated $\mathrm{THz}$ frequency waveguide concepts [2-13]. As the waveguides increase in quality, the next step is to make functional $\mathrm{THz}$ waveguide devices.

A $\mathrm{THz}$ directional coupler has been previously reported [3], where the coupling was achieved by placing two fibers in close proximity. However, both fibers were subwavelength-sized rod-in-air type fibers $[2-5,7,12]$. The advantage of such a rod-in-air fiber is that the $\mathrm{THz}$ field has a small overlap with the lossy waveguide material. However, these fibers have the disadvantage that they are difficult to handle, because any contact on the surface disturbs the field and leads to a large scattering loss.

Here we present the first broadband directional fiber coupler working in the $\mathrm{THz}$ regime that confines the $\mathrm{THz}$ radiation to a core surrounded by a structured cladding. This fiber is much better suited for handling and as an element in advanced photonic $\mathrm{THz}$ devices. The broadband functionality is achieved by downdoping the cores of a dual-core photonic crystal fiber (PCF). The downdoping is done mechanically by introducing subwavelength holes into both cores. This could also be achieved by chemical downdoping, but this would be experimentally more difficult. The downdoped cores experience mode field diameter minima, leading to frequency ranges of constant coupling lengths, as suggested by Lægsgaard et al. [14]. In addition to broadband coupling, the proposed coupler has also a short coupling length, which is a necessary property considering that the material loss is high in the THz regime. We have previously demonstrated that the drill-and-draw technique used for the fabrication of microstructured polymer optical fibers [15] is also well suited for manufacturing $\mathrm{THz}$ fibers [13].

We consider the coupler made as a dual-core PCF using the polymer Topas as the background material $[16,17]$. Topas is a nonpolar cyclic-olefin copolymer, whose amorphous structure gives it, in the $\mathrm{THz}$ range, an approximately 100 times lower loss than that of polymethyl methacrylate [13]. Additionally, the refractive index of Topas has a near-constant value of $n=1.5258 \pm$ $2 \times 10^{-4}$ in the $0.1-1.5 \mathrm{THz}$ range [13]. The proposed fiber has a pitch $(\Lambda)$ of $750 \mu \mathrm{m}$ and a hole diameter $(d)$ of $300 \mu \mathrm{m}$, giving a hole-diameter-to-pitch ratio $(d / \Lambda)$ of
0.40 . The fiber has two cores separated by a center-tocenter distance of twice the pitch. In each core there is a region that is mechanically downdoped by a triangular microstructure with a pitch $\Lambda_{c}$ and hole diameter $d_{c}$, as seen in Fig. 1.

The dual-core fiber will support two fundamental modes for each polarization, one even and one odd mode. The difference in the propagation constant between these modes gives the coupling length. For simplicity, only the results of one polarization are presented. The coupling length is the length required before achieving a $\pi$ phase change between the two modes, $L_{c}=\frac{\pi}{\left|\beta_{e}-\beta_{o}\right|}$, where $\beta_{e}$ and $\beta_{o}$ are the propagation constants for the even and odd modes, respectively. The effective refractive index of the core modes is calculated using the MIT Photonic-Bands (MPB) Package [18] with a $9 \Lambda \times 9 \frac{\sqrt{3}}{2} \Lambda$ supercell using $600 \times 600$ grid points.

The fiber parameters affecting the coupling length are the pitch, the hole size, the size of the doped region, and the dopant level. The pitch and hole size are fixed. Given that the structure is designed to be endlessly single mode, it does not support any higher-order modes. The fiber guidance is, however, limited by two factors. For frequencies below $0.3 \mathrm{THz}$, the wavelength of the radiation is too large to be confined efficiently to the core, and the confinement loss rises rapidly. At very high frequencies, the waveguide is sensitive to bending and handling, because the core mode is highly sensitive to microbending [19]. The high-frequency cutoff of the waveguide with an undoped core is not relevant in this Letter. However, as we downdope the core of the coupler, we shift the

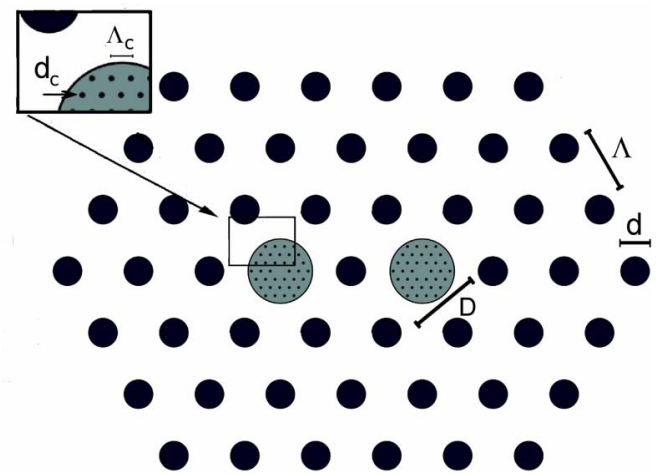

Fig. 1. (Color online) Broadband THz coupler design with mechanically downdoped cores. All the considered designs have a pitch of $\Lambda=750 \mu \mathrm{m}$ and hole-to-pitch ratio of $d / \Lambda=0.40$. 
high-frequency cutoff of the core modes to lower frequencies. This is illustrated in Fig. 2(a), where the effective refractive index of the odd mode is plotted together with the fundamental space-filling mode (FSM). The effective index of the modified cores crosses the FSM at $1.9 \mathrm{THz}$ for $d_{c} / \Lambda_{c}=0.105$ and at $1.3 \mathrm{THz}$ for $d_{c} / \Lambda_{c}=$ 0.145 , where $\Lambda_{c}=97.5 \mu \mathrm{m}$. This crossing coincides with the sudden increase in the coupling length seen in Fig. 2(b). As the frequency approaches this crossing, the core modes will start coupling with the cladding modes. We define the bandwidth $(B)$ of the coupling as the frequency range where the coupling length is the same within $\pm 5 \%$. Apart from the bandwidth requirement, the coupler should also be short, because the inherent material loss is high in the $\mathrm{THz}$ regime, even for Topas. The coupling length is shown in Fig. 2(b) for a normal coupler and for six mechanically downdoped couplers. The three high-frequency mechanically
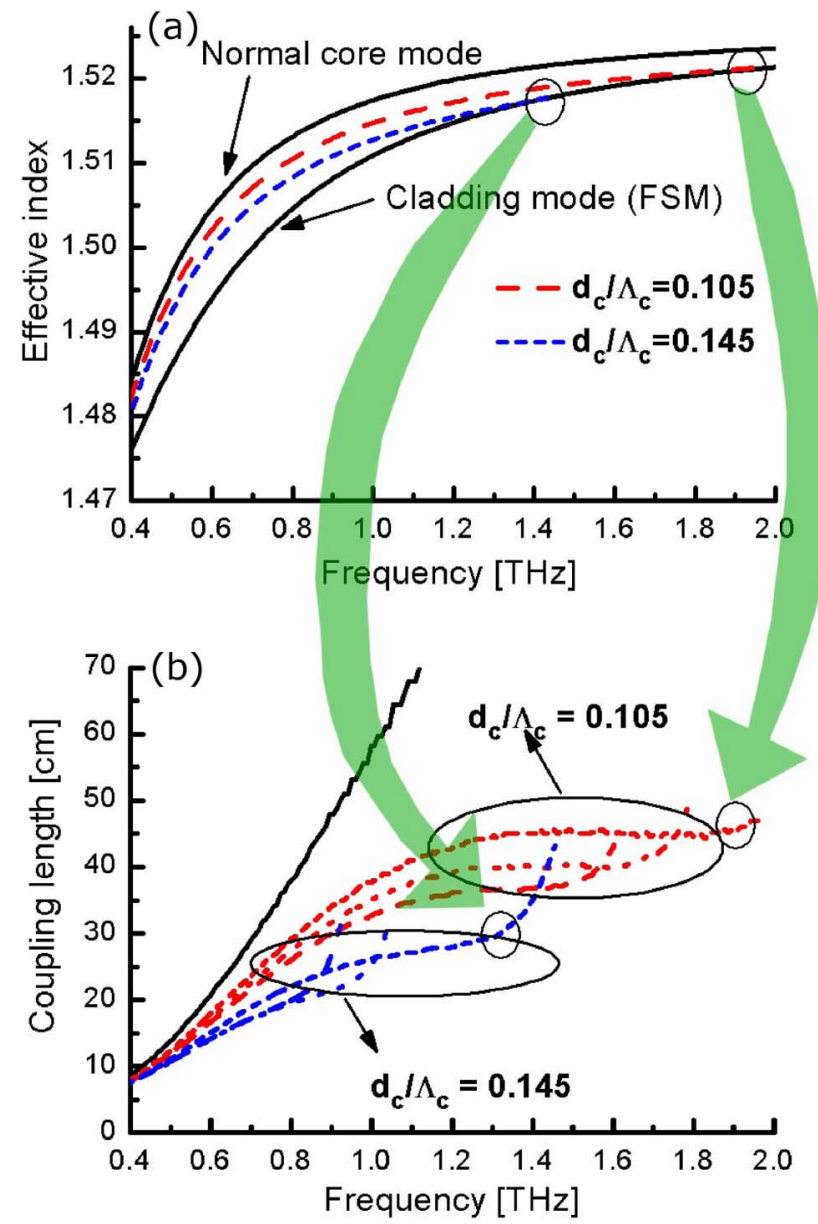

Fig. 2. (Color online) (a) Effective refractive index of the odd modes of doped coupler designs with $\Lambda_{c}=97.5 \mu \mathrm{m}, d_{c} / \Lambda_{c}=$ 0.105 (red long-dashed curve), and $d_{c} / \Lambda_{c}=0.145$ (blue short-dashed curve). The top solid curve (black) is the index of the odd mode of the undoped core coupler, while the bottom solid curve (black) is the FSM. (b) Coupling length of a normal coupler (solid) and downdoped couplers (dotted and dashed). Red curves have $\Lambda_{c}=97.5 \mu \mathrm{m}$ (short dashed), $\Lambda_{c}=108.75 \mu \mathrm{m}$ (dotted) and $\Lambda_{c}=120 \mu \mathrm{m}$ (long dashed). Blue curves have $\Lambda_{c}=97.5 \mu \mathrm{m}$ (short dashed), $\Lambda_{c}=127.5 \mu \mathrm{m}$ (dotted) and $\Lambda_{c}=$ $150 \mu \mathrm{m}$ (long dashed). The large green arrows indicate where the cutoff of the odd mode in (a) leads to an abrupt increase in the coupling length in (b).

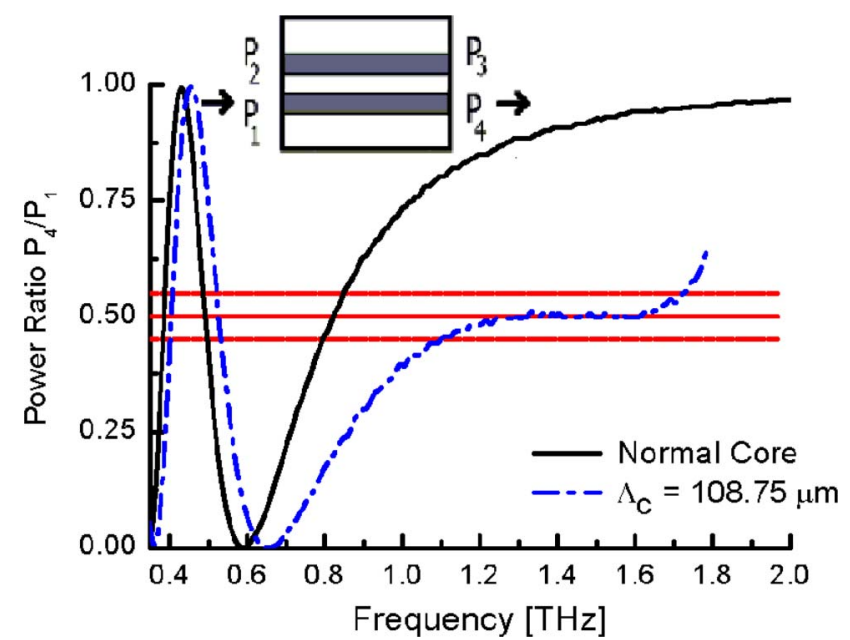

Fig. 3. (Color online) Normalized output from the launch arm of a 20-cm-long coupler. The undoped coupler (solid) crosses the $50 \%$ region rapidly and therefore has a narrow bandwidth. The microstructured coupler has a plateau around 50\% centered at $1.4 \mathrm{THz}$ and therefore has a broad bandwidth at $1.4 \mathrm{THz}$. In this case, $d_{c} / \Lambda_{c}=0.105$.

downdoped couplers all have the same hole-to-pitch ratio of $d_{c} / \Lambda_{c}=0.105$, while the three low-frequency downdoped couplers all have a hole-to-pitch ratio of $d_{c} / \Lambda_{c}=$ 0.145 . In general, we can state that the coupler with large $d_{c} / \Lambda_{c}$ have the shortest coupling length, while the couplers with the small $d_{c} / \Lambda_{c}$ have the broader bandwidth. Thus a dual-core fiber of this design with two microstructured cores with a pitch of $108.75 \mu \mathrm{m}$ and a $d_{c} / \Lambda=0.105$ can be used as a $3 \mathrm{~dB}$ coupler centered at $1.4 \mathrm{THz}$, provided the fiber is $20 \mathrm{~cm}$ long, corresponding to half the coupling length $L_{c}$.

The fraction of power at the output of the launch arm $\left(P_{4}\right)$ of both a downdoped coupler and an undoped coupler for this device length is shown in Fig. 3. The fraction of power at the output of the launch arm is given by $P_{4} / P_{1}=\cos ^{2}\left(L_{d} / L_{c} \cdot \pi / 2\right)$, where $L_{d}$ is the device length and $L_{c}$ is the coupling length. From Fig. 3 it is clear that

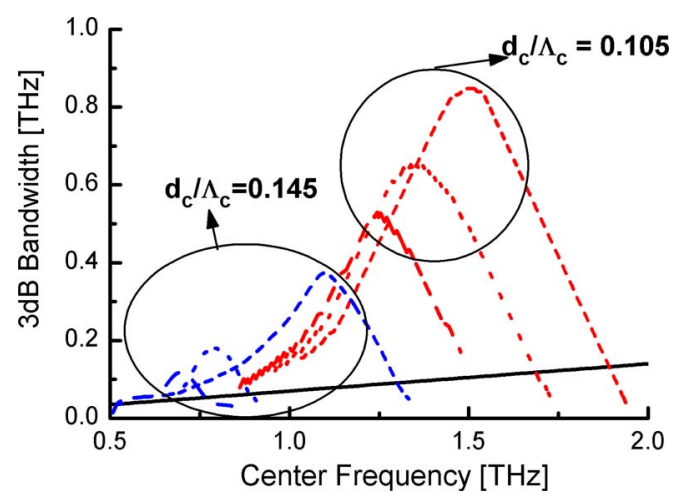

Fig. 4. (Color online) Center frequency versus $3 \mathrm{~dB}$ bandwidth. The solid curve (black) is the undoped coupler. The three high-frequency designs (red) have $d_{c} / \Lambda_{c}=0.105$, while the three low-frequency designs (blue) have $d_{c} / \Lambda_{c}=0.145$. In the high-frequency case, the short dashed curve has $\Lambda_{c}=97.5 \mu \mathrm{m}$, the dotted curve has $\Lambda_{c}=108.75 \mu \mathrm{m}$, and the dashed curve has $\Lambda_{c}=120 \mu \mathrm{m}$. In the low-frequency case, the short dashed curve has $\Lambda_{c}=97.5 \mu \mathrm{m}$, the dotted curve has $\Lambda_{c}=127.5 \mu \mathrm{m}$, and the dashed curve has $\Lambda_{c}=150 \mu \mathrm{m}$. 


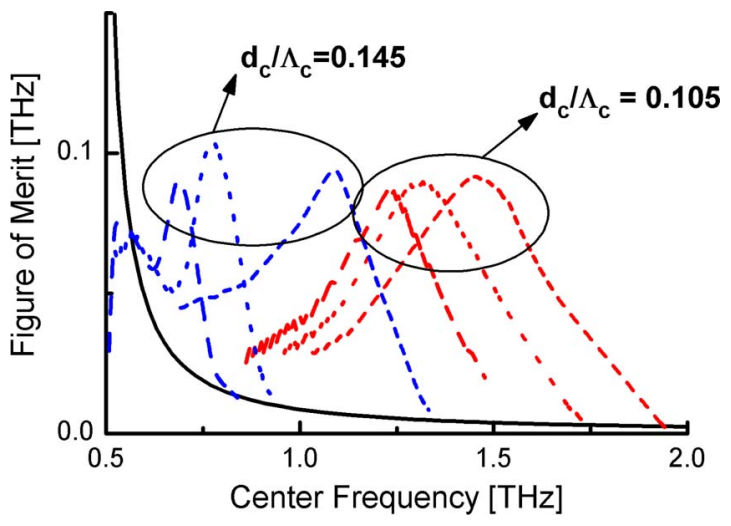

Fig. 5. (Color online) FOM arranged as in Fig. $\underline{4}$.

the downdoped coupler has a much broader $3 \mathrm{~dB}$ bandwidth than the normal coupler and also at a higher frequency for the same device length. If the normal coupler was to have the same center frequency, the device length would have to be more than twice as long.

The $3 \mathrm{~dB}$ bandwidth versus center frequency is shown in Fig. 4 for a lossless coupler. The $d_{c} / \Lambda_{c}=0.105$ have the broadest bandwidth because their high-frequency cutoff lies on a more flat part of the FSM curve seen in Fig. 2(a). However, the loss is neglected and these couplers have the longest device length of around $20 \mathrm{~cm}$, so despite the broad bandwidth, they might not be the best choice.

In order to take into consideration both the bandwidth $(B)$ and the material loss $[\alpha(\omega)]$, we define the figure of merit $(\mathrm{FOM})=\frac{B}{\alpha(\omega) L_{d}}$. A large FOM requires now both a short device length and a broad bandwidth. It is important to keep in mind that the material loss is frequency dependent and that, in the $\mathrm{THz}$ range of interest, the loss rises almost linearly. The loss rises at a rate of $0.36 \mathrm{~cm}^{-1} / \mathrm{THz}$ from $0.06 \mathrm{~cm}^{-1}$ at $0.4 \mathrm{THz}$ [13]. The calculated FOM is shown in Fig. 5, where it now becomes clear how crippling the material loss is. Now the lowfrequency couplers are better than the high-frequency couplers, and at very low frequencies, the normal coupler even has the best FOM. As previously stated, the same results can be achieved by chemical downdoping. To get similar results, as, for example, the $\Lambda=108.75 \mu \mathrm{m}$ coupler, a circular region with diameter $D=0.88 \times \Lambda$ in the center of the two cores must be downdoped by $0.5 \%$.

In conclusion, we have demonstrated a broadband coupler design for $\mathrm{THz}$ applications by using mechani- cally downdoped cores. Bandwidths in excess of $0.8 \mathrm{THz}$ are achievable at around $1.5 \mathrm{THz}$. The coupling length has also been shortened by the downdoping, compared to a normal coupler. We have introduced a new FOM, which takes into account both bandwidth and loss. This FOM shows that a smaller bandwidth at a lower frequency is more useful than a large bandwidth at high frequency, simply due to the high loss.

The authors would like to thank J. Lægsgaard for stimulating discussions.

\section{References}

1. M. Tonouchi, Nature Photon. 1, 97 (2007).

2. A. Hassani, A. Dupuis, and M. Skorobogatiy, Appl. Phys. Lett. 92, 071101 (2008).

3. A. Dupuis, J. F. Allard, D. Morris, K. Stoffler, C. Dubois, and M. Skorobogatiy, Opt. Express 17, 8012 (2009).

4. S. Atakaramians, V. Afshar, B. M. Fischer, D. Abbott, and T. M. Monro, Opt. Express 16, 8845 (2008).

5. S. Atakaramians, V. Afshar, B. M. Fischer, D. Abbott, and T. M. Monro, Opt. Commun. 282, 36 (2009).

6. G. Gallot, S. P. Jamison, R. W. McGowan, and D. Grischkowsky, J. Opt. Soc. Am. B 17, 851 (2000).

7. R. Mendis and D. Grischkowsky, J. Appl. Phys. 88, 4449 (2000).

8. R. Mendis and D. Grischkowsky, Opt. Lett. 26, 846 (2001).

9. R. Mendis and D. Grischkowsky, IEEE Microw. Wireless Compon. Lett. 11, 444 (2001).

10. B. Bowden, J. A. Harrington, and O. Mitrofanov, Opt. Lett. 32, 2945 (2007).

11. K. Wang and D. M. Mittleman, Nature 432, 376 (2004).

12. L. J. Chen, H. W. Chen, T. F. Kao, J. Y. Lu, and C. K. Sun, Opt. Lett. 31, 308 (2006).

13. K. Nielsen, H. K. Rasmussen, A. J. L. Adam, P. C. M. Planken, O. Bang, and P. U. Jepsen, Opt. Express 17, 8592 (2009).

14. J. Lægsgaard, O. Bang, and A. Bjarklev, Opt. Lett. 29, 2473 (2004).

15. M. A. van Eijkelenborg, M. C. J. Large, A. Argyros, J. Zagari, S. Manos, N. A. Issa, I. Bassett, S. Fleming, R. C. McPhedran, C. M. de Sterke, and N. A. P. Nicorovici, Opt. Express 9, 319 (2001).

16. G. Emiliyanov, J. B. Jensen, O. Bang, P. E. Hoiby, L. H. Pedersen, E. M. Kjær, and L. Lindvold, Opt. Lett. 32, 460 (2007).

17. G. Emiliyanov, J. B. Jensen, O. Bang, P. E. Hoiby, L. H. Pedersen, E. M. Kjaer, and L. Lindvold, Opt. Lett. 32, 1059 (2007).

18. S. G. Johnson and J. D. Joannopoulos, Opt. Express 8, 173 (2001).

19. N. A. Mortensen and J. R. Folkenberg, J. Opt. A 5, 163 (2003). 